\title{
Quality of life in noncompliant adults with phenylketonuria after resumption of the diet
}

\author{
M. Bik-Multanowski • B. Didycz $\cdot$ R. Mozrzymas • \\ M. Nowacka $\cdot$ L. Kaluzny $\cdot$ W. Cichy $•$ B. Schneiberg • \\ J. Amilkiewicz • A. Bilar • M. Gizewska • \\ A. Lange • E. Starostecka • A. Chrobot • \\ B. I. Wojcicka-Bartlomiejczyk • A. Milanowski
}

Published online: 12 January 2009

(C) SSIEM and Springer 2009

\section{Erratum to: J Inherit Metab Dis Short Report \#133 (2008) Online DOI 10.1007/s10545-008-0978-7}

The following Acknowledgement was omitted from the text:

The study was sponsored by the Nutricia Foundation Research Grant and by government grant for scientific research (NN402329233).

The online version of the original article can be found at http://dx.doi.org/10.1007/s10545-008-0978-7.

\author{
M. Bik-Multanowski $(\square) \cdot$ B. Didycz \\ Chair of Pediatrics, Jagiellonian University, \\ ul. Wielicka 265, 30-663 Krakow, Poland \\ e-mail: m.bik@wp.pl \\ R. Mozrzymas \\ Voivodeship Hospital, Wrocław, Poland \\ M. Nowacka $\cdot$ A. Milanowski \\ Department of Pediatrics, Institute of Mother and Child, \\ Warsaw, Poland \\ L. Kaluzny $\cdot$ W. Cichy \\ Department of Pediatric Gestroenterology and Metabolism, \\ Medical University, Poznan, Poland \\ B. Schneiberg \\ Chair and Department of Pediatrics, \\ Children Nephrology and Endocrinology, \\ Silesian Medical Academy, Zabrze, Poland
}

J. Amilkiewicz

Children's Clinical Hospital,

Lublin, Poland

A. Bilar $\cdot$ M. Gizewska

II Department of Pediatrics,

Pomeranian Medical Academy,

Szczecin, Poland

A. Lange $\cdot$ E. Starostecka

Metabolic Department,

Polish Mother's Health Memorial Institute,

Łódź, Poland

A. Chrobot

Voivodeship Hospital, Bydgoszcz, Poland

B. I. Wojcicka-Bartlomiejczyk

Polish PKU Working Group,

Warsaw, Poland 